Atomic and molecular processes

Atomic Processes and Applications. (In Honour of David R. Bate's 60th Birthday.) Edited by P. G. Burke and B. L. Moiseiwitsch. Pp. $\mathrm{x}+533$. (NorthHolland: Amsterdam, New York and Oxford, 1976.) Dfl.165; $\$ 65.95$.

THIS book forms a remarkable tribute to the scientific work in atomic and molecular physics over the past 40 years of David R. Bates' life. The scene is set in a perceptive and affectionate tribute to David Bates on his sixtieth birthday by Sir Harrie Massey, who begins by recalling his first meeting with Bates when, in 1934, he went to Queen's University, Belfast, as Lecturer in Mathematical Physics. Bates was one of the group of able young men from Ulster attracted by Massey to work in theoretical physics. The work based on their cooperation first at Belfast, then at University College, London, and later, also, in the school founded by David Bates when he returned as Professor to Queen's University in 1951, represents a large part of the progress made over this period in the study of atomic and molecular processes. It is indeed a striking example of the influence of the great leader and teacher in science that so many of the authors of anticles in this book have been students at Queen's University. All of them have more or less close connections with either University College, London or Queen's. In this respect, it is not surprising that the book conveys an extraordinary sense of family.

Apart from the introductory tribute by Sir Harrie Massey, the thirteen articles which make up the book form a highly readable account of the present state of progress in the study of atomic processes. The first three articles deal with the Earth's atmosphere: $M$. Nicolet on Stratospheric Aeronomy, J. C. G. Walker on the Upper Atmosphere, and M. B. McElroy on Problems in Atmospheric Pollution. M. Nicolet considers the principal reactions first in an oxygen atmosphere, then in turn adding hydrogen, nitrogen and halogens. The theoretical problem of stratospheric ozone is resolved and the situation concerning minor constituents described. J. C. G. Walker provides an admirable summary of present knowledge of the chemistry of the $E$ and $F$ regions, stressing the importance in the understanding of the phenomena of dissociative recombination of mole- cular ions as the process for removing ions and electrons, as first suggested by Bates and Massey in 1947. M. B. McElroy, in an excellent account of man's impact on the global environment, pays tribute to the classic contribution of Bates and Witherspoon (1952).

The theme of molecules in interstellar space is taken up by A. Dalgarno, who deals with formation and destruction mechanisms for $\mathrm{CH}$ and $\mathrm{CH}^{+}$. The problem posed for the abundance of $\mathrm{CH}^{+}$by the existence of molecular hydrogen in interstellar clouds, is considered. The process of di-electronic recombination of special interest in connection with the solar corona, is the subject of a theoretically interesting treatment by M. J. Seaton and P. J. Storey.

The remaining eight chapters of the book are devoted to an authoritative series of reviews of some of the main fields of study in atomic and molecular processes. Pioneering contributions were made in many of these by David Bates, and he has continued to contribute to them up to the present day. Photoionisation of atomic systems and electron scattering by atoms are the subject of masterly reviews by $\mathrm{P} . \mathrm{G}$. Burke and M. C. McDowell. B. L. Moiseiwitsch and A. L. Stewart contribute chapters, respectively, on negative ions and oscillator strengths. There is a thought-provoking chapter on computational methods by I. C. Percival.

\section{Earth pictures}

Mission to Earth: Landsat Views the World. By N. M. Short, P. D. Lowman, Jr, S. C. Freden and W. A. Finch, Jr. (NASA : Washington, DC, 1976.) \$14.

LANDSAT, launched in 1972, was the first of a generation of unmanned satellites dedicated to repetitive surveillance of the continents and adjacent coastal waters to gather data for a variety of practical applications in Earth Resources disciplines, such as cartography, geological mapping, mineral resource evaluation, water inventory, coast and wetlands management, land-use assessment, and so on.

The above publication contains some 400 colour plates of outstanding Landsat pictures of areas all over the World, compiled and selected from more than 100,000 processed and reconstructed images, obtained during its first four years of operation. Each plate is accompanied by a carefully prepared narrative caption, summarising notable
The book concludes with three chapters on ionic recombination and atomic collision processes by M. R. Flannery, R. McCarroll, K. L. Bell and A. E. Kingston. Throughout this series of chapters, it is fascinating to follow the increased understanding which has come from the use of atomic models of increasing sophistication and from the growth of computational facilities. Another interesting aspect is the balance of success in appropriate régimes of quantal semi-classical and classical methods.

The editors are to be congratulated on the volume of work which they have brought together. The presentation is of uniform clarity and free, as far as 1 could detect, from all but the most trivial misprints. It must be a great joy to Professor Bates to have gathered together for him by this group of his students, colleagues and friends a description of a scientific edifice which he helped to found and did so much to build. Apart from this celebratory aspect the book is to be recommended as providing an admirable description of the state of the art in the study of atomic processes, which are of such increasing impontance in a growing number of fields of interest in contemporary physics.

J. C. Gunn

J. C. Gunn is Professor of Natural Philosophy at the University of Glasgow. Scotland, UK.

features. Taking into account that these photographs were available anyway from their Earth Resources program, it can only be warmly welcomed that NASA has made this selection of outstanding pictures available to the general public at the comparatively low price of $\$ 14$. These photographs are likely to be of great interest not only to the various resource specialists amongst the appropriate Government authorities in the various countries concerned, but also to the serious teachers and students in geography, geology and allied disciplines, and to the general public with an interest in travel and geography.

Copies and slides of individual photographs are also obtainable, as well as free copies of an educational supplement, the Educator's Guide, which provides a general description of the Landsat program, the operation of the satellite and an explanation of remote sensing and imagery with suggested classroom uses of the material.

P. Schagen

P. Schagen works in the Applied Physics Division at the Philips Research Laboratories, Surrey, UK. 